\title{
On a $T_{1}$ Study of Molecular Motion in Some Tetra Substituted Ammonium Halides
}

\author{
Fevzi Köksal \\ Department of Physics, Faculty of Sciences, Ankara University, Turkey
}

Z. Naturforsch. 34a, 1296-1300 (1979); received August 9, 1979

The spin-lattice relaxation times of tetramethylammonium bromide $\left(\mathrm{CH}_{3}\right)_{4} \mathrm{NBr}$, iodide $\left(\mathrm{CH}_{3}\right)_{4} \mathrm{NI}$, tetraethylammonium chloride $\left(\mathrm{CH}_{3} \mathrm{CH}_{2}\right)_{4} \mathrm{NCl}$, bromide $\left(\mathrm{CH}_{3} \mathrm{CH}_{2}\right)_{4} \mathrm{NBr}$, iodide $\left(\mathrm{CH}_{3} \mathrm{CH}_{2}\right)_{4} \mathrm{NI}$, tetrapropylammonium iodide $\left[\mathrm{CH}_{3}\left(\mathrm{CH}_{2}\right)_{2}\right]_{4} \mathrm{NI}$, tetrabutylammonium bromide $\left[\mathrm{CH}_{3}\left(\mathrm{CH}_{2}\right)_{3}\right]_{4} \mathrm{NBr}$, iodide $\left[\mathrm{CH}_{3}\left(\mathrm{CH}_{2}\right)_{3}\right]_{4} \mathrm{NI}$, tetraheptylammonium bromide $\left[\mathrm{CH}_{3}\left(\mathrm{CH}_{2}\right)_{6}\right]_{4} \mathrm{NBr}$ and iodide $\left[\mathrm{CH}_{3}\left(\mathrm{CH}_{2}\right)_{6}\right]_{4} \mathrm{NI}$ were measured at $60 \mathrm{MHz}$ in the temperature interval $100 \mathrm{~K}$ to near the melting points. Two minima of $T_{1}$ were observed for tetramethylammonium halides, for tetraethylammonium bromide and iodide and for tetrapropylammonium iodide. The minima in $T_{1}$ were attributed to $\mathrm{CH}_{3}$ group reorientations and reorientations of the tetramethyl, ethyl and propylammonium cations. The activation energies of the processes were determined.

\section{Introduction}

Motional properties of compounds of the type $\left(\mathrm{CH}_{3}\right)_{4} \mathrm{X}$ where $\mathrm{X}$ is $\mathrm{C}, \mathrm{Si}, \mathrm{Ge}, \mathrm{Sn}, \mathrm{Pb}$ and $\left(\mathrm{CH}_{3}\right)_{4} \mathrm{AsZ}$ where $\mathrm{Z}$ is $\mathrm{Cl}, \mathrm{Br}$ and $\mathrm{I}$ were studied by broad line $\mathrm{nmr}$ and pulsed nmr techniques $[1-7]$. In addition, $\left(\mathrm{CH}_{3}\right)_{4} \mathrm{NZ}$ type compounds were studied [8] at $25.3 \mathrm{MHz}$ and two minima were observed at $T_{1}$. One of these minima was attributed to $\mathrm{CH}_{3}$ group reorientations and the other to reorientations of the cations in the compounds. Therefore it seemed interesting to study larger molecules and it is the purpose of this study to investigate the motional properties of tetramethylammonium (TMA) bromide, iodide; tetraethylammonium (TEA) chloride, bromide iodide; tetrapropylammonium (TPA) iodide, tetrabutylammonium (TBA) bromide, iodide; tetraheptylammonium (THA) bromide and iodide by pulsed $\mathrm{nmr}$ at $60 \mathrm{MHz}$.

\section{Experimental Considerations and Results}

The spin-lattice relaxation time measurements were performed at $60 \mathrm{MHz}$ using an SXP type 4$100 \mathrm{MHz}$ Bruker pulse spectrometer employing $180^{\circ}-\tau-90^{\circ}$ pulse sequence. The compounds were obtained from commercial sources, and before use they were dried under $10^{-3}$ torr vacuum for two days by keeping the samples at $323 \mathrm{~K}$. The samples were $0,8 \mathrm{~cm}$ in diameter and $0,3 \mathrm{~cm}$ in hight and the measurements were made between 100 and

Reprint requests to Dr. F. Köksal, A. Ư. Fen Fakültesi Fizik Bölümü, Beşevler-Ankara, Trukey.
$490 \mathrm{~K}$. The temperature control system used was a Bruker B-ST 100/700 controller. Most of the measurements were repeated three times and found to be well reproducible.

The experimental values of $T_{1}$ were plotted against $10^{3} \mathrm{~K} / T$ as shown in Figures $1-10$. For TMA bromide the spin-lattice relaxation time passes through two minimum at 323 and $385 \mathrm{~K}$ with $T_{1}=29 \mathrm{~ms}$ and $T_{1}=38 \mathrm{~ms}$, respectively. The $T_{1}$ of TMA iodide also passes through two minima at $308 \mathrm{~K}$ with $T_{1}=29 \mathrm{~ms}$ and at $355 \mathrm{~K}$ with $T_{1}=36 \mathrm{~ms}$.

For TEA chloride we observed only a minimum at $130 \mathrm{~K}$ with $T_{1}=80 \mathrm{~ms}$; because of its low melting point we did not go to higher temperatures. However for TEA bromide the experiments were made between 485 and $120 \mathrm{~K}$, and $T_{1}$ passes through two minima at $166 \mathrm{~K}$ with $T_{1}=86 \mathrm{~ms}$ and at $425 \mathrm{~K}$ with $T_{1}=1.6 \mathrm{~s}$. Similarly, for TEA iodide we observed two minima at $113 \mathrm{~K}$ with $T_{1}=42 \mathrm{~ms}$ and at $444 \mathrm{~K}$ with $T_{1}=2.3 \mathrm{~s}$.

For TPA iodide the experiments were made between 485 and $120 \mathrm{~K}$ and two minima in $T_{1}$ were observed. One of the minima occurs at $158 \mathrm{~K}$ with $T_{1}=86 \mathrm{~ms}$ and the other at $400 \mathrm{~K}$ with $T_{1}=0.28 \mathrm{~s}$.

For TBA bromide and iodide the experiments were performed between 335 and $100 \mathrm{~K}$. Due to their low melting points we did not go to higher temperatures, and only one minimum was observed for each of the compounds. The $T_{1}$ minimum for TBA bromide occurs at $125 \mathrm{~K}$ with $T_{1}=80 \mathrm{~ms}$ and for TBA iodide the minimum occurs at $154 \mathrm{~K}$ with $T_{1}=80 \mathrm{~ms}$.

0340-4811 / 79 / 1100-1296 $\$ 01.00 / 0$. - Please order a reprint rather than making your own copy. 


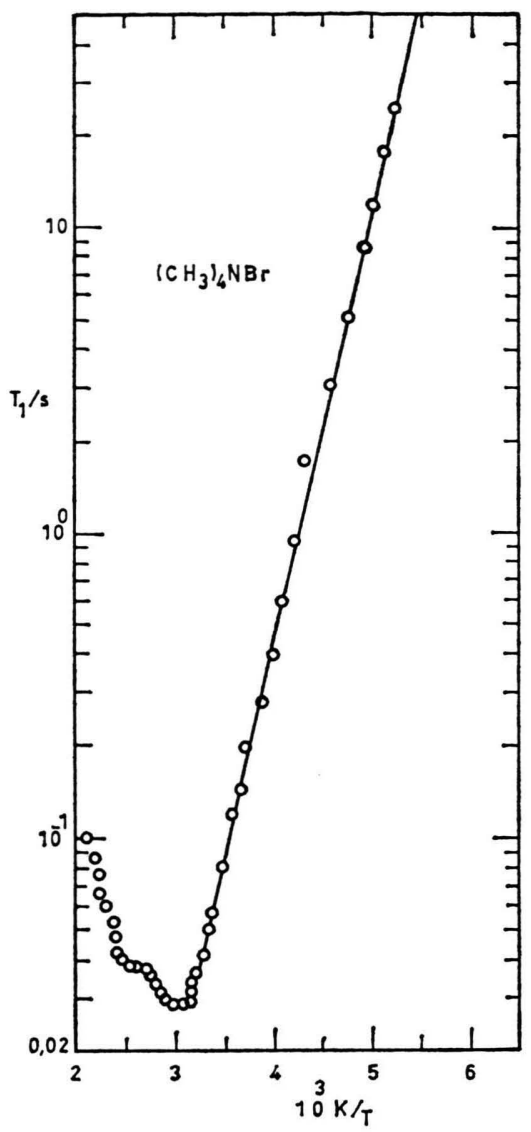

Fig. 1. Spin-lattice relaxation time of TMA bromide against $10^{3} \mathrm{~K} / \mathrm{T}$.

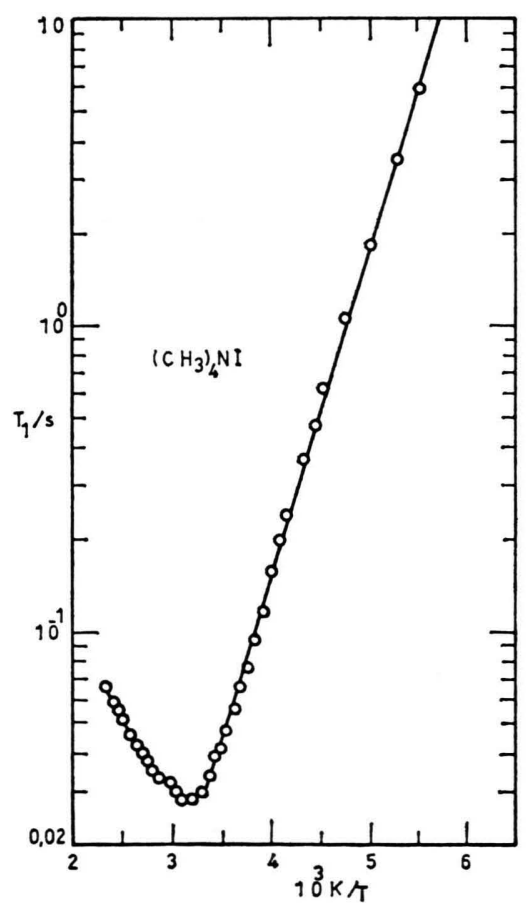

Fig. 2. Spin-lattice relaxation time of TMA iodide against $10^{3} \mathrm{~K} / \mathrm{T}$.

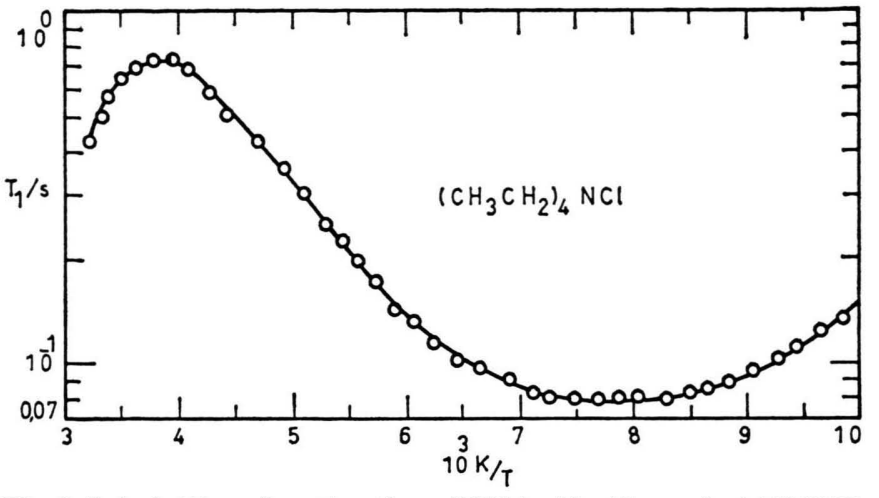

Fig. 3. Spin-lattice relaxation time of TEA chloride against $10^{3} \mathrm{~K} / \mathrm{T}$.

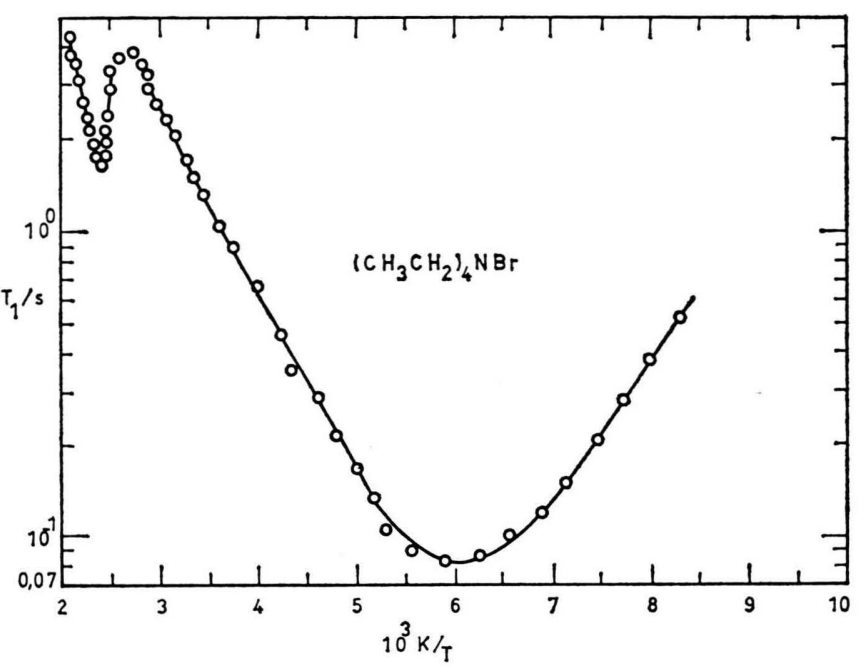

Fig. 4. Spin-lattice relaxation time of TEA bromide against $10^{3} \mathrm{~K} / \mathrm{T}$.

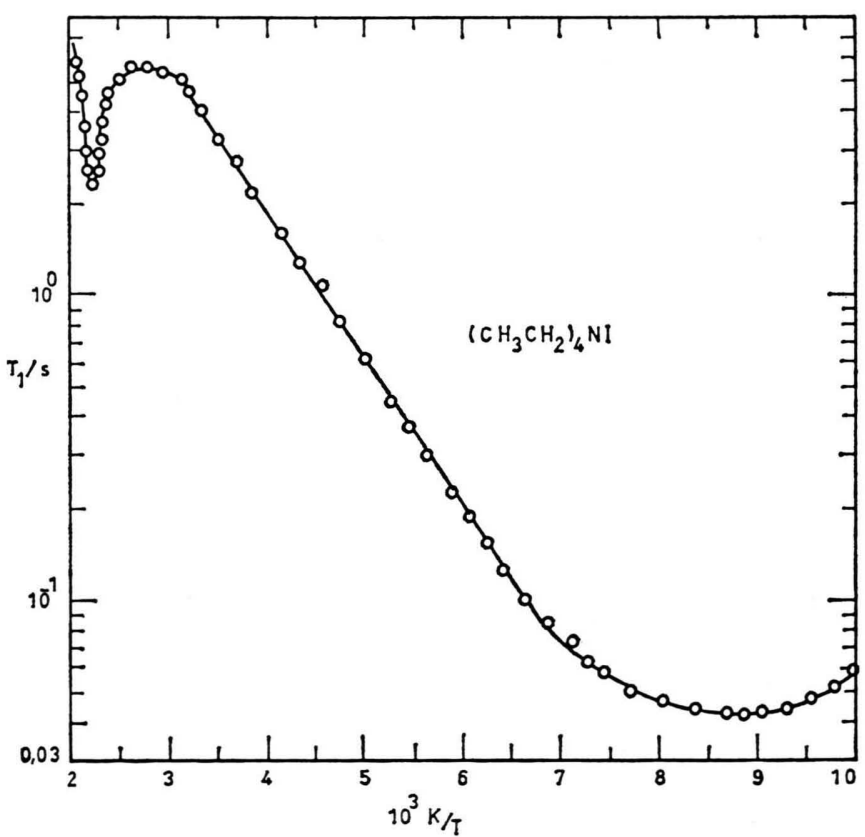

Fig. 5. Spin-lattice relaxation time of TEA iodide against $10^{3} \mathrm{~K} / \mathrm{T}$. 


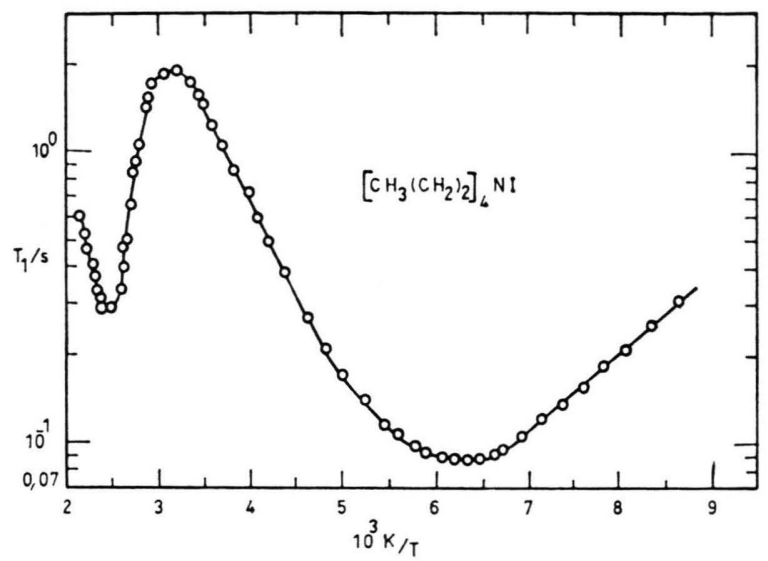

Fig. 6. Spin-lattice relaxation time of TPA iodide against $10^{3} \mathrm{~K} / \mathrm{T}$.

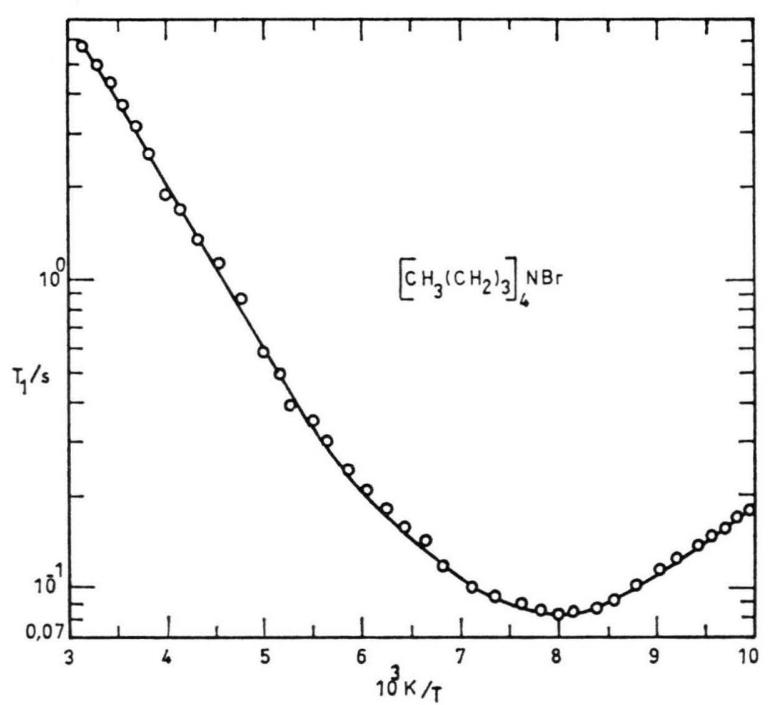

Fig. 7. Spin-lattice relaxation time of TBA bromide against $10^{3} \mathrm{~K} / \mathrm{T}$.

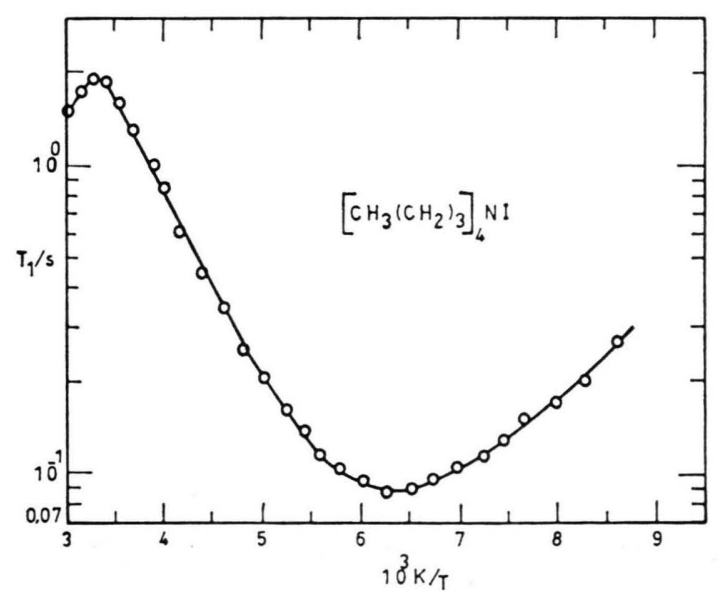

Fig. 8. Spin-lattice relaxation time of TBA iodide against $10^{3} \mathrm{~K} / \mathrm{T}$.

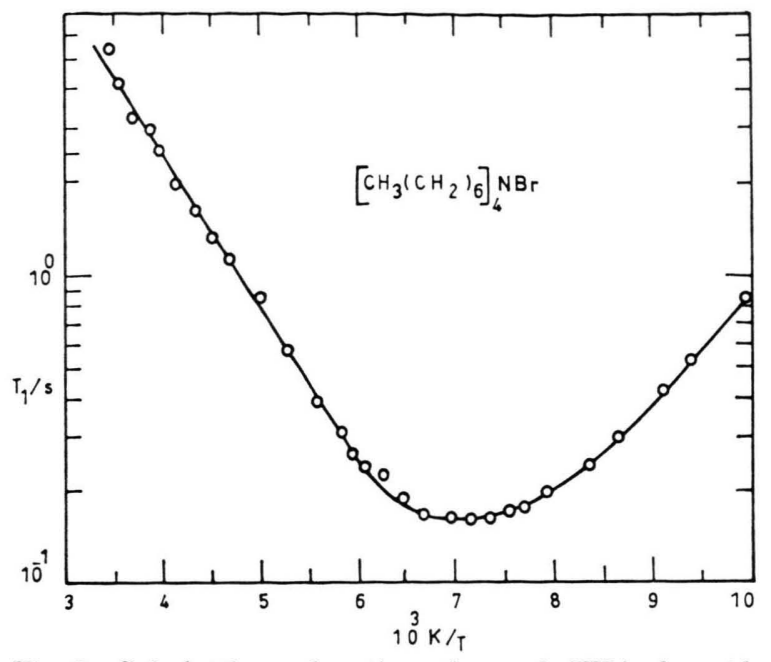

Fig. 9. Spin-lattice relaxation time of THA bromide against $10^{3} \mathrm{~K} / \mathrm{T}$.

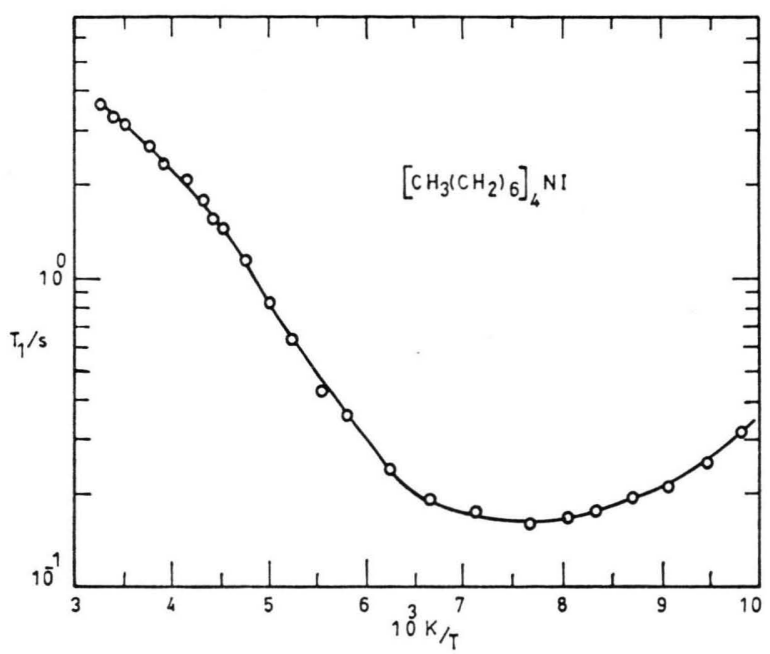

Fig. 10. Spin-lattice relaxation time of THA iodide against $10^{3} \mathrm{~K} / \mathrm{T}$.

For THA bromide and iodide the $T_{1}$ minima occur respectively at 130 and $138 \mathrm{~K}$ and the minimum values of $T_{1}$ are equal and $T_{1}=0.16 \mathrm{~s}$.

\section{Analysis of Results}

The two minima in $T_{1}$ for TMA bromide and iodide indicate two types of motion as explained by Albert et al. [8]. The low temperature minima were attributed to methyl group reorientations, and the high temperature minimum were attributed to reorientational motions of the $\left(\mathrm{CH}_{3}\right)_{4} \mathrm{~N}$ cation. The calculated spin-lattice relaxation rate including tho proton-proton dipolar interactions in the methyl groups and the intra methyl group dipolar inter- 
actions within the same molecule is given by [8]

$$
T_{1}^{-1}=A g\left(\omega_{0}, \tau_{\mathrm{c} 2}\right)+B g\left(\omega_{0}, \tau_{\mathrm{c} 1}\right),
$$

where $g\left(\omega_{0}, \tau_{\mathrm{c} i}\right)$ are the spectral density functions and

$$
A=\frac{9}{20} \frac{\gamma^{4} \hbar^{2}}{r^{6}}, \quad B=\frac{3}{20} \frac{\gamma^{4} \hbar^{2}}{r^{6}}+\frac{27}{10} \frac{\gamma^{4} \hbar^{2}}{r_{1}{ }^{6}} .
$$

Furthermore,

$$
\tau_{\mathrm{c} 2}^{-1}=\tau_{c}^{-1}+\tau_{\mathrm{c} 1}^{-1} .
$$

In these equations $\tau_{\mathrm{c}}$ is the correlation time for methyl group reorientations, $\tau_{\mathrm{c} 1}$ the correlations time for the reorientations of the cation, $\omega_{0}$ is the Larmor frequency, $r$ is the proton-proton distance within the methyl group and $r_{1}$ is the distance between the centers of the methyl groups within the same molecule. When $\tau_{\mathrm{c}} \ll \tau_{\mathrm{c} 1}$ the minimum value of $T_{1}$ can be written [6]

$$
T_{1 \min }^{-1}=\frac{9}{20} \frac{\gamma^{4} \hbar^{2}}{r^{6}} \frac{1.43}{\omega_{0}} .
$$

Incorporation of the usual constants and $r=1.79 \AA$ in (3) gives $T_{1 \mathrm{~min}}=34 \mathrm{~ms}$. The low temperature experimental $T_{1}$ minima for TMA bromide and iodide are equal and $29 \mathrm{~ms}$. This is somewhat shorter than the calculated value, however the discrepancy is not great and comes from the dipolar interactions between the methyl group within the same molecule. The correlation times where supposed to satisfy the Arrhenius equation

$$
\tau_{\mathrm{c} i}=\tau_{\mathrm{ci}}^{0} \exp \left(E_{\mathrm{a}} / R T\right),
$$

and the activation energy $E_{\mathrm{a}}$ corresponding to the linear portion above the low temperature minimum in Fig. 1 was found to be $2.1 \mathrm{kcal} \mathrm{mol}^{-1}$. The activation energy corresponding to the linear portion above the second minimum is $5.7 \mathrm{kcal} \mathrm{mol}^{-1}$. The activation energy for methyl group reorientations in TMA iodide cannot be obtained from the experimental results due to the short temperature interval between the minima. But the activation energy above the high temperature minimum was found to be $5.6 \mathrm{kcal} \mathrm{mol}^{-1}$. These activation energies are smaller than the value obtained by Albert et al. [8], but the frequency dependence of the low temperature experimental $T_{1}$ minima for both compounds agree with the frequency ratio to $25.3 \mathrm{MHz}$ at which the experiments were performed. Furthermore our $E_{\mathrm{a}}=2.1 \mathrm{kcal} \mathrm{mol}^{-1}$ for methyl group reorientations is in agreement with the $E_{\mathrm{a}}$ 's of methyl groups reported by several authors $[2,3$, $5,6,7,9]$.

For TEA chloride we have observed only one minimum in $T_{1}$ and the $T_{1 \mathrm{~min}}=89 \mathrm{~ms}$ does not agree with the calculated $T_{1 \mathrm{~min}}=34 \mathrm{~ms}$. The activation energy corresponding to the linear portion in Fig. 3 is found to be $2.0 \mathrm{kcal} \mathrm{mol}^{-1}$. However for TEA bromide and iodide we have observed two minima in $T_{1}$ which again can be attributed to methyl group reorientations and cation reorientations. The activation energies above the low temperature minima are 2.7 and $2.2 \mathrm{kcal} \mathrm{mol}^{-1}$ and the activation energies above the high temperature minima are 10.2 and $10.3 \mathrm{kcal} \mathrm{mol}^{-1}$, respectively, for TEA bromide and iodide. Although the low temperature minimum of TEA bromide does not agree with the calculated result, the $T_{1}$ minimum for TEA iodide is $42 \mathrm{~ms}$, which is close to the calculated $34 \mathrm{~ms}$. This discrepancy between the observed and calculated minimum values of $T_{1}$ may be due to a nonrandomness in the reorientations of the methyl group about its threefold axis at low temperatures. A discrepancy like here was also encountered by Reilly et al. [9] at the reorientations of the methyl group in methyl ammonium aluminum sulfate.

For TPA iodide there are two minima in $T_{1}$, and again the low temperature minimum does not agree with the calculated result. The activation energy corresponding to the linear portion above the low temperature minimum was found to be $2.3 \mathrm{kcal} \mathrm{mol}^{-1}$ and that above the high temperature minimum $11 \mathrm{kcal} \mathrm{mol}^{-1}$.

For TBA bromide and iodide the activation energies were found to be 2.5 and $2.8 \mathrm{kcal} \mathrm{mol}^{-1}$, respectively. The activation energies for THA bromide and iodide in Figs. 9 and 10 are 2.2 and $2.0 \mathrm{kcal} \mathrm{mol}-1$. The experimental $T_{1}$ minima, $160 \mathrm{~ms}$, for THA halides are much longer than the predicted $34 \mathrm{~ms}$. This difference and the somewhat low activation energies for the relaxation seem to suggest quantum mechanical torsional state effects [10] rather than classical reorientation of the methyl groups at low temperatures. On the other hand $\mathrm{CH}_{2}$ protons certainly have longer $T_{1}$ 's than $\mathrm{CH}_{3}$ protons, and due to spin-exchange averaging the observed single $T_{1}$ 's for TEA, TPA, TBA and THA halides can be expected to be longer than those for TMA halides, which include no $\mathrm{CH}_{2}$ groups. Also 
this may be the reason for the discrepancies between the experimental and the calculated $T_{1}$ minima for TEA, TPA, TBA, and THA halides.

[1] J. G. Powles and H. S. Gutowsky, J. Chem. Phys. 21, 1695 (1953).

[2] E. O. Stejskal, D. E. Woessner, T. C. Farrar, and H. S. Gutowsky, J. Chem. Phys. 31, 55 (1959).

[3] G. W. Smith, J. Chem. Phys. 42, 4229 (1965).

[4] S. Albert and J. A. Ripmeester, J. Chem. Phys. 57, 2642 (1972).

[5] T. T. Ang and B. A. Dunell, Can. J. Chem. 54, 1985 (1976).
This study was supported in part by the Magnetic Resonance Research Unit of TBTAK (Turkish Scientific and Technical Research Council).

[6] F. Köksal, J. Chem. Soc., to be published.

[7] T. T. Ang and B. A. Dunell, J. Chem. Soc. Faraday Trans. 2, 75, 169 (1979).

[8] S. Albert, H. S. Gutowsky, and J. A. Ripmeester, J. Chem. Phys. 56, 3672 (1972).

[9] D. E. O'Reilly and T. Tsang, Phys. Rev. 157, 417 (1967).

[10] P. S. Allen and S. Clough, Phys. Rev. Letters 22, 1351 (1969). 